\title{
Canadian French Translation of The Couples Satisfaction Index: A Pre-Validation Pilot Study Exploring Men's Perspective
}

Jalila Jbilou ( $\square$ jalila.jbilou@umoncton.ca )

Université de Moncton

Andréanne Charbonneau

Université de Moncton

René-Pierre Sonier

Université de Moncton

Paul S. Greenman

Université du Québec en Outaouais

Natasha Levesque

Université de Moncton

Sophie Barriault

Université de Moncton

Véronique Sonier

Université de Moncton

Jean Grenier

Institut du Savoir Montfort

Marie-Hélène Chomienne

University of Ottawa

\section{Research Article}

Keywords: Instrument translation, reliability, couple satisfaction, men's health

Posted Date: August 20th, 2021

DOl: https://doi.org/10.21203/rs.3.rs-799178/v1

License: (c) (i) This work is licensed under a Creative Commons Attribution 4.0 International License.

Read Full License 


\section{Abstract \\ Background}

It is imperative for health care professionals to have access to valid and reliable tools to evaluate the quality of romantic relationships, as it has been repeatedly shown to be related to psychological and physical health outcomes. The Couples Satisfaction Index (CSI) was developed to address the shortcomings of the most widely cited measures of satisfaction by increasing precision and power of measurement. However, the use of this questionnaire is limited due to a lack of translated versions. The purpose of the current study was therefore to translate the CSI to Canadian French (CanFrench-CSI) and to evaluate its reliability in a sample of male Canadians.

\section{Methods}

The CSI questionnaire was adapted and translated into Canadian French using a forward-backward approach. Its reliability was then evaluated by means of Cronbach's alpha internal consistency coefficients, corrected item-total correlation coefficients, and a test-retest intraclass correlation coefficient at a two-week interval.

\section{Results}

Data from 53 men in committed relationships were analyzed. The French adaptation of the CSI demonstrated satisfactory internal consistency and test-retest reliability.

\section{Conclusions}

Overall, the results provided evidence supporting the translation consistency and reliability of the CanFrench-CSI, and thus, paved the way for further research on romantic relationships and health outcomes among French-speaking individuals.

\section{Background}

Close personal relationships such as marriage and romantic relationships have been consistently associated with health outcomes [1, 2]. Indeed, there is much evidence of the beneficial effects of relationship status and relationship satisfaction on mental and physical health $[2,3]$. For instance, individuals in committed relationships are less likely to experience mental health problems and to be overweight in comparison with single individuals [1]. It is also well established that marriage promotes longevity of life [4]. Yet, research indicates that simply being in a committed relationship does not necessarily have beneficial effects in and of itself. In fact, troubled relationships tend to elevate health risks $[2,3]$. These findings underline the determinant role of relationship satisfaction in the pathway from 
romantic relationship to health outcomes. Relationship satisfaction has been associated with personal well-being [5], global happiness [6], mental health [7], physical health [2], and longer lifespan [8], whereas relationship dissatisfaction has been shown to increase mental and physical health problems [3].

Researchers have investigated the implications of these associations for individuals living with a chronic physical disease (i.e., cardiac disease, diabetes, or cancer). Robles et al.'s [2] meta-analysis revealed negative relationships between marital quality and risks of mortality among individuals with chronic conditions, particularly in studies addressing end-stage renal disease and cardiovascular diseases. In Isiozor et al.'s study [9], perceived level of marriage dissatisfaction was associated with an increased risk of sudden cardiac death among Caucasian men, independently of conventional and emerging risk factors. Their results revealed that dissatisfied married men have about $86 \%$ higher risk of sudden cardiac death when compared to men in very satisfying marriages. These findings are consistent with those of earlier studies that have reported a link between marriage satisfaction and cardiovascular health $[2,10,11]$.

Nonetheless, discrepancies have been identified when studying sex/gender differences. In their review of the associations between marital relationship and physical health, Kiecolt-Glaser and Newton [6] reported that being married is more protective for men's health, whereas being in an unsatisfying marriage is more detrimental for women's health. However, a recent meta-analysis showed rather few moderation effects of gender in the associations between marital satisfaction and health outcomes [2].

Like most variables in the field of social sciences, relationship satisfaction is primarily measured with self-report questionnaires. Several tools have been developed to assess individuals' satisfaction of their relationship. The Couples Satisfaction Index (CSI) was developed by Funk and Rogge [12], using item response theory, to measure individuals' satisfaction in their relationship. The CSI is a self-report questionnaire that can be used as a 32,16 , or 4 -item scale. The three versions of the CSI scale have lengths appropriate for a variety of different applications. Indeed, marital treatment studies benefit from the higher levels of precision and information offered by the 32-item scale, whereas the brevity of the 4item scale is useful for national surveys. The 4-item scale consists of items $1,12,19$, and 22 from the complete 32-item version, while the 16-item scale is composed of items 1, 5, 9, 11, 12, 17, 19, 20, 21, 22, $26,27,28,30,31$, and 32 . In the 32 -item version, the first item of the questionnaire is answered on a 7point Likert scale, ranging from 0 (extremely unhappy) to 6 (perfect), whereas the following 24 items use a variety of response anchors, all with 6-point Likert scales ranging from 0 (e.g., "always disagree") to 5 (e.g., "always agree"). The final seven items require the participant to describe how they feel about their relationship using 6-point semantic differential scales ranging from 0 (e.g., "boring") to 5 (e.g., "interesting"). One item of the CSI scales states "I have a warm and comfortable relationship with my partner". Total scores of the 32-item scale can range from 0 to 161, with higher scores indicating greater relationship satisfaction. Scores falling below 104.5 suggest notable relationship dissatisfaction [12].

Funk and Rogge [12] have documented the acceptable psychometric properties of the CSI scales. All three versions of the scale have demonstrated excellent internal consistency, with Cronbach's alpha coefficients 
ranging from .94 to .98 . Their strong correlations with other well-established measures of relationship satisfaction (e.g., Marital Adjustment Test and Dyadic Adjustment Scale) and anchor scales of constructs theoretically related to relationship satisfaction (e.g., Communication Patterns Questionnaire and Conflict

subscale of the Marital Coping Inventory) offer solid evidence of their convergent and construct validity, respectively. The CSI scales have also shown to discriminate between distressed and non-distressed relationships extremely well, and to have a high precision of measurement. Indeed, a test information curves analysis revealed that both the 32-item scale and the 16-item scale provide notably more information than do the Marital Adjustment Test and the Dyadic Adjustment Scale, for all but the most satisfied respondents. In turn, the enhanced precision of the scales led to an increase in their power for detecting differences in levels of satisfaction. As stated by Funk and Rogge [12], these results suggest that the CSI scales allow researchers to reduce measurement error and gain power without increasing the length and administration time.

Altogether, the English versions of the CSI scales have proven to be valid and reliable in assessing relationship satisfaction among married individuals and unmarried romantic partners. However, due to a lack of translated versions, its use is limited to a small portion of the population. While the CSI has already been translated to Russian [13] and Persian [14], its use has not yet been extended to Frenchspeaking populations. The aim of the current study is therefore to address this gap in the literature in order to allow for more research with this tool and to enhance researchers' understanding of the associations between relationship satisfaction and health outcomes. More precisely, the objectives of this pilot study are to translate the CSI into French and to test its reliability with a small sample of men in New Brunswick and Québec. It is particularly important to analyze the psychometric properties of the CSI separately for men and women to determine whether gender-based differential item functioning exists [12]. As such, this study will provide key information for a larger study.

\section{Methods}

\section{French translation procedure}

As argued by Kristjansson and colleagues [15], the translation procedure plays a crucial role in the overall validity and reliability of the adaptation of an existing instrument. Hence, the translation of the CSI followed a rigorous process to provide conformity between its English and its French version. The 32-item CSI scale was translated into Canadian French (CanFrench-CSI) using the forward-backward approach proposed by the Mapi Research Institute [16]. Three (3) forward translations were first produced by bilingual research professionals from different scientific backgrounds (health policy sciences, biochemistry, and public health). They each independently translated the original CSI questionnaire items from English to French. The three translators and the principal study investigator then reviewed and compared each item of the translated versions. Inconsistencies or differences between versions were discussed (with the principal investigator acting as referee) to produce one common consensus translation. Agreement among translators was measured using the Cohen's kappa coefficient, which was developed to calculate inter-rater reliability [17]. Once a unique French version of the CSI was created, two 
research professionals with no knowledge of the original version independently back-translated the French version into English to ensure the accuracy of the translated version. The two back-translations were compared with the original CSI by the multidisciplinary committee to assess equivalence. Excellent concordance was achieved (98\%), and thus, the unique French translation was considered as the provisional version of the CanFrench-CSI. To ensure further validity of the provisional CanFrench-CSI version, a pre-test was conducted with six (6) men. The purpose of the pre-test was to provide an evaluation of the quality of the translation, the comprehensibility of its content, and the feasibility of the instrument (time requirement). Participants were also given the opportunity to provide written recommendations aimed at improving comprehensibility of the items. Although minimal changes were made to the CanFrench-CSI after the pre-test, a final version of the CanFrench-CSI was developed based on this feedback (supplementary file: Appendix A).

\section{Participants}

Participation in this two-part study was solicited through media calls, invitation posters displayed in the community, and presentations during community organizations meetings (i.e., Lions Club, Rotary Club, and Knights of Columbus). The inclusion criteria were as follows: (1) being a native French speaker, (2) being over 19 years of age, and (3) being located in New Brunswick or Québec, Canada. Participants also had to have been in a stable romantic relationship for at least 12 months prior to the study (married, common law or dating). Of the 64 men recruited between June and October 2018, 53 (83\%) were eligible and returned both administrations of the questionnaire (100\%). Sample characteristics are reported in Table 1.

\section{Measures}

Sociodemographic characteristics. Personal information such as age, race/ethnicity, sexual orientation, marital status, education, occupation, and gross household income was collected through a demographic questionnaire.

Couples Satisfaction Index. Participants completed the CanFrench-CSI twice; first at baseline (T1) and then two weeks later (T2).

\section{Data analysis}

Internal reliability for the CanFrench-CSI was assessed at both time points using Cronbach alpha coefficients, with values greater than .70 suggesting acceptable internal consistency [18]. Corrected itemtotal correlations were also evaluated to define each items' association with the total score on the other items. Strong positive correlations (greater than .5) are considered evidence of good relationship of items with the construct. To assess test-retest reliability, intraclass correlations coefficients were computed. Values greater than .75 are indicative of good stability over time [19].

\section{Ethical considerations}


Before conducting this pilot study, the Research Ethics Committee of the Université de Moncton, New Brunswick, Canada, reviewed and approved the research proposal (Dossier n-1718-044). Participants were informed, by writing, about the purpose of the study, the principles of voluntary participation, and the procedures to be undertaken. They were asked to complete the questionnaire two weeks apart and were informed that they could withdraw from the study at any time without having to justify their decision. Participants first provided written informed consent, then completed the questionnaire. They received a \$25 gift card after completing the T2-questionnaire.

\section{Results}

The CanFrench-CSI's reliability was tested using the entire sample of men $(N=53)$. The questionnaire demonstrated moderate to high internal consistency. Indeed, global scores exceeded reliability standards of .70 at both time points, with Cronbach's alpha coefficients of .88 at baseline and .89 two weeks later. As shown in Table 2, corrected item-total correlations were also computed for all 32 items of the CanFrench-CSI at T1 and T2. Results at T1 revealed that 13 out of 32 items had corrected item-total correlations inferior to .50 , with 6 values being negative. At T2, 14 items had corrected item-total correlations inferior to .50 and one of these correlations was negative. Finally, temporal stability was measured with test-retest reliability and revealed satisfactory results for the CanFrench-CSI's global score $(r=.89, p<.01)$.

\section{Discussion}

The goals of this study were to provide the first French version of the Couples Satisfaction Index (CSI) and to examine its reliability with a small sample of French-speaking men from the general population in Canada. Over the years, relationship dissatisfaction has repeatedly been linked to negative physical and psychological outcomes $[2,13,14,20,21,22,23]$. Since language also has a determinant role in health [24], there is evident need to validate translated relationship satisfaction scales, such as the CSI. Doing so will allow for more research with this tool, and consequently, help gain a better understanding of the associations between relationship satisfaction and health outcomes among French-speaking couples.

Results of the current study yield the first satisfactory elements regarding the psychometric properties of the CanFrench-CSI. Indeed, support for reliability was provided by Cronbach's alphas and test-retest correlations, even though not all corrected item-total coefficients were of acceptable values. Cronbach alpha coefficients for the total score of our French translation of the CSI at both time points were superior to the cut-off criteria of .70 proposed by Nunnally and Bernstein [18]. These results suggest that the CanFrench-CSI's satisfactory internal consistency is quite similar to that of its English version, found in Funk and Rogge's [12] research. In addition, test-retest reliability with a two-week interval revealed a strong positive coefficient of .89, exceeding the recommended cut-off criteria of .75 [19]. To the best of our knowledge, our pilot study provides the first evidence for the temporal stability of the CSI.

\section{Sex/gender}


The CSI was not initially adapted with a sex or gender perspective, but rather as a couple's perspective. Indeed, it was developed to assess relationship satisfaction among married or romantic couples. It is therefore critical to evaluate the psychometric properties of the CSI scales separately for men and women in order to verify whether any gender-based differences in the functioning of items exist [12]. It is important to do so by collecting data from individuals rather than couples to reduce participation bias and enrich the diversity of the sample. Indeed, requiring data from both partners in a relationship have been found to diminish the overall variability in relationship satisfaction and individual characteristics [25]. It has also been suggested that discussions between romantic partners at the prospect of participating in a relationship study could compromise data quality [25]. As such, the present study provided an opportunity to ensure men's understanding of the translated items and to evaluate their perspective without the influence of their partners' point of view.

\section{Clinical implications}

Over the years, empirical findings have continuously linked poor relationship satisfaction with negative physical and mental health outcomes. For example, it has been shown that poor relationship quality is associated with elevated ambulatory blood pressure [26], therefore increasing the risk of sudden cardiac death among men [9]. Many researchers have also documented a link between unsatisfying relationship and relationship dissolutions, thus leading to subsequent negative effects on health and wellness of the individuals terminating the relationship [20]. By translating the CSI into French, the current study provides therapists and psychologists serving French populations a reliable instrument capable of measuring relationship satisfaction, which in turn, may enhance their ability to identify problems in married or romantic couples, promote health, and decrease risks.

Moreover, growing evidence suggests that romantic partners' mutual influence can have both beneficial and harmful effects on health [3]. Although relationship satisfaction has been associated with positive health outcomes at the individual level [2], research suggests that the health of individuals in satisfying relationships may be at greater risk when their romantic partner is suffering [3]. Hence, the inclusion of relationship satisfaction questionnaires in therapeutic interventions and health promotion techniques could not only potentially benefit individuals with health problems, but also their partners.

\section{Limitations}

Despite the promising findings supporting the reliability of the CanFrench-CSI, a few limitations merit notice. To begin with, the present study did not consider the composition of the sample. Indeed, all participants were Caucasian and heterosexual men, which limits the generalizability of our results to the whole population. A second concern would be the size of our sample. With a sample size of only 53 participants, we did not meet the appropriate guidelines to validate a questionnaire [27]. Another limitation of this study is that we collected data from only one member per couple, thus prohibiting analyses examining couple congruence over perceived relationship satisfaction. This limitation was also reported by Funk and Rogge [12] when they developed the CSI scales. 


\section{Future directions}

As mentioned by Funk and Rogge [12], some items of the CSI may be more or less informative of global relationship satisfaction for specific subgroups of participants (e.g., men and women). Identifying these measurement biases could help researchers appropriately interpret CSI scores for all groups. Considering this, future research should expand upon our results by including dyads to fully examine the validity of our French adaptation of the scale. Finally, seeing that the present study was not able to do so, validity analyses should be of utmost importance in future studies.

\section{Conclusions}

Our work contributes to increase the quality of research on romantic relationships and health among French-speaking individuals by translating a French adaptation of the CSI and providing preliminary information on its reliability. Overall, the CanFrench-CSI demonstrated satisfactory internal consistency and test-retest reliability, and thus, shows promise as a reliable measure of satisfaction to be used in clinical practice to improve health outcomes and decrease health risks. Yet, further research with diverse French subgroups is needed to establish the validity of our French translation of the questionnaire.

\section{List Of Abbreviations}

CanFrench-CSI Canadian French version of Couples Satisfaction Index

CSI Couples Satisfaction Index

T1 First administration (Baseline)

T2 Second administration (2 weeks after the first administration)

\section{Declarations}

Ethics approval and consent to participate: This pilot study was approved (Dossier n-1718-044) by the Research Ethics Committee of the Université de Moncton, New Brunswick, Canada, and has been performed in accordance with the ethical standards of the institution. Informed consent was obtained from all individual participants included in the study.

Consent for publication: Not applicable.

Availability of data and materials: The data that support the findings of this study are available upon request from the corresponding author.

Competing interests: The authors declare that they have no conflict of interest. 
Funding: This research was supported by the New Brunswick Health Research Foundation. The first author $(\mathrm{JJ})$ received logistic and financial support from the Centre de formation médicale du NouveauBrunswick to support this publication.

Authors' contributions: All authors have contributed significantly to the design of the project, the planning, the conduct of the data collection, the data analysis and/or in the manuscript editing. All authors contributed to review and approve the final manuscript.

Acknowledgements: The authors would like to thank Kim Bossé for her support with participants' recruitment and data collection. They also would like to thank men who have participated to this study.

\section{References}

1. Braithwaite SR, Delevi R, Fincham FD. Romantic relationships and the physical and mental health of college students. Pers Relatsh. 2010;17(1):1-12. https://doi.org/10.1111/j.1475-6811.2010.01248.x.

2. Robles TF, Slatcher RB, Trombello JM, McGinn MM. Marital quality and health: A meta-analytic review. Psychol Bull. 2014;140(1):140-187. https://doi.org/10.1037/a0031859

3. Kiecolt-Glaser JK, Wilson SJ. Lovesick: How couples' relationships influence health. Annu Rev Clin Psychol. 2017;13:421-443. https://doi.org/10.1146/annurev-clinpsy-032816-045111

4. August KJ, Kelly CS, Markey, CN. Marriage, romantic relationships, and health. In: Friedman HS (Editor). Encyclopedia of mental health. 2nd ed. Waltham: Academic Press; 2016. p. 46-52. https://doi.org/10.1016/B978-0-12-397045-9.00074-4

5. Proulx CM, Helms HM, Buehler C. Marital quality and personal well-being: A meta-analysis. J Marriage Fam. 2007;69(3):576-593. https://doi.org/10.1111/j.1741-3737.2007.00393.x

6. Kiecolt-Glaser JK, Newton TL. Marriage and health: His and hers. Psychol Bull. 2001;127(4):472503. https://doi.org/10.1037/0033-2909.127.4.472

7. Tulloch H, Bouchard K, Clyde MJ, Madrazo L, Demidenko N, Johnson S, Greenman P. Learning a new way of living together: A qualitative study exploring the relationship changes and intervention needs of patients with cardiovascular disease and their partners. BMJ Open. 2020;10(5):e032948. https://doi.org/10.1136/bmjopen-2019-032948

8. Whisman MA, Gilmour AL, Salinger JM. Marital satisfaction and mortality in the United States adult population. Health Psychol. 2018;37(11):1041-1044. https://doi.org/10.1037/hea0000677

9. Isiozor NM, Kunutsor SK, Laukkanen T, Kauhanen J, Laukkanen JA. Marriage dissatisfaction and the risk of sudden cardiac death among men. Am J Cardiol. 2019;123(1):7-11.

https://doi.org/10.1016/j.amjcard.2018.09.033

10. Liu H, Waite L. Bad marriage, broken heart? Age and gender differences in the link between marital quality and cardiovascular risks among older adults. J Health Soc Behav. 2014;55(4):403-423. https://doi.org/10.1177/0022146514556893 
11. Robles TF, Kiecolt-Glaser JK. The physiology of marriage: Pathways to health. Physiol Behav. 2003;79(3):409-16. https://doi.org/10.1016/s0031-9384(03)00160-4

12. Funk JL, Rogge RD. Testing the ruler with item response theory: Increasing precision of measurement for relationship satisfaction with the Couples Satisfaction Index. J Fam Psychol. 2007;21(4):572583. https://doi.org/10.1037/0893-3200.21.4.572

13. Okhotnikov IA, Wood ND. Adaptation of the Couples Satisfaction Index into Russian. Contemp Fam Ther. 2020;42(2):140-151. https://doi.org/10.1007/s10591-019-09517-6

14. Forouzesh Yekta F, Yaghubi H, Mootabi F, Roshan R, Gholami Fesharaki M, Omidi A. Psychometric characteristics and factor analysis of the Persian version of Couples Satisfaction Index. Avicenna J Neuropsychophysiology. 2017;4(2):49-56. http://dx.doi.org/10.32598/ajnpp.4.2.49

15. Kristjansson EA, Desrochers A, Zumbo B. Translating and adapting measurement instruments for cross-linguistic and cross-cultural research: A guide for practitioners. Can J Nurs Res. 2003;35(2):127-42.

16. Acquadro C, Conway K, Hareendran A, Aaronson N. Literature review of methods to translate healthrelated quality of life questionnaires for use in multinational clinical trials. Value Health. 2008;11(3):509-521. https://doi.org/10.1111/j.1524-4733.2007.00292.x.

17. McHugh ML. Interrater reliability: The kappa statistic. Biochem Med (Zagreb). 2012;22(3):276-82.

18. Nunnally JC, Bernstein IH. Psychometric Theory. 3rd ed. New York: McGraw Hill; 1994. 736 p.

19. Koo TK, Li MY. A guideline of selecting and reporting intraclass correlation coefficients for reliability research. J Chiropr Med. 2016;15(2):155-163. https://doi.org/10.1016/j.jcm.2016.02.012

20. Carr D, Springer KW. Advances in families and health research in the 21 st century. J Marriage Fam. 2010;72(3):743-761. http://dx.doi.org/10.1111/j.1741-3737.2010.00728.x.

21. de Montigny F, Meunier S, Cloutier L, Tremblay G, Coulombe S, Auger N, et al. Spousal positive social control and men's health behaviors and self-efficacy: The influence of age and relationship satisfaction. J Soc Pers Relat. 2017;34(5):753-770. http://dx.doi.org/10.1177/0265407516658362.

22. Lamela D, Figueiredo B, Morais A, Matos $P$, Jongenelen I. Are measures of marital satisfaction valid for women with depressive symptoms? The examination of factor structure and measurement invariance of the Couple Satisfaction Index-4 across depression levels in Portuguese women. Clin Psychol Psychother. 2020;27(2):214-219. https://doi.org/10.1002/cpp.2420

23. Mattson RE, Rogge RD, Johnson MD, Davidson EKB, Fincham FD. The positive and negative semantic dimensions of relationship satisfaction. Pers Relatsh. 2013;20(2): 328-355. https://doi.org/10.1111/j.1475-6811.2012.01412.x

24. de Moissac D, Bowen S. Impact of language barriers on access to healthcare for official language minority Francophones in Canada. Healthc Manage Forum. 2017;30(4):207-212. https://doi.org/10.1177/0840470417706378.

25. Barton AW, Lavner JA, Stanley SM, Johnson MD, Rhoades GK. "Will you complete this survey too?" Differences between individual versus dyadic samples in relationship research. J Fam Psychol. 2020;34(2):196-203. http://dx.doi.org/10.1016/j.jad.2013.08.013 
26. Baker B, Helmers K, O'Kelly B, Sakinofsky I, Abelsohn A, Tobe S. Marital cohesion and ambulatory blood pressure in early hypertension. Am J Hypertens. 1999;12(2 Pt 1):227-230. https://doi.org/10.1016/s0895-7061(98)00184-8.

27. Tsang S, Royse CF, Terkawi AS. Guidelines for developing, translating, and validating a questionnaire in perioperative and pain medicine. Saudi J Anaesth. 2017;11(Suppl 1):S80-S89. https://doi.org/10.4103/sja.SJA_203_17

\section{Tables}

Table 1. Descriptive Data $(N=53)$ 


\begin{tabular}{|c|c|}
\hline Sociodemographic variables & $N(\%)$ \\
\hline \multicolumn{2}{|l|}{ Age (years) } \\
\hline$\leq 29$ & $5(9.4)$ \\
\hline $30-39$ & $3(5.7)$ \\
\hline $40-49$ & $11(20.7)$ \\
\hline $50-59$ & $16(30.2)$ \\
\hline$\geq 60$ & $17(32.1)$ \\
\hline Missing & $1(1.9)$ \\
\hline \multicolumn{2}{|l|}{ Ethnicity } \\
\hline White & $53(100)$ \\
\hline \multicolumn{2}{|l|}{ Sex orientation } \\
\hline Heterosexual & $53(100)$ \\
\hline \multicolumn{2}{|l|}{ Educational level } \\
\hline 8th grade & $6(11.3)$ \\
\hline High school (without diploma) & $13(24.5)$ \\
\hline High school (with diploma) & $14(26.4)$ \\
\hline College diploma/certificate & 19 (35.9) \\
\hline Undergraduate degree & $1(1.9)$ \\
\hline \multicolumn{2}{|l|}{ Marital status } \\
\hline Married & $37(69.8)$ \\
\hline Common-law union & $16(30.2)$ \\
\hline \multicolumn{2}{|l|}{ Income } \\
\hline$<25000 \$$ & $4(7.5)$ \\
\hline $25000-59999 \$$ & $22(41.5)$ \\
\hline$\geq 60000 \$$ & $23(43.5)$ \\
\hline Prefer not to answer & $4(7.5)$ \\
\hline \multicolumn{2}{|l|}{ Employment } \\
\hline Full-time employee & $32(60.4)$ \\
\hline Part-time employee & $4(7.5)$ \\
\hline Full-time self-employed & $6(11.3)$ \\
\hline
\end{tabular}




$\begin{array}{ll}\text { Part-time self-employed } & 1(1.9) \\ \text { Unemployed } & 1(1.9) \\ \text { Retired } & 7(13.2) \\ \text { Other } & 2(3.8)\end{array}$

Table 2. Corrected item-total correlation for the CanFrench-CSI at times of measures (T1 and T2). 
1. Veuillez indiquer, tout bien considéré, votre niveau global de bonheur par rapport à votre relation de couple

2. Temps passé ensemble

3. Prise de décisions majeures

4. Démonstration d'affection

5. En général, comment souvent pensez-vous que les choses entre vous et votre partenaire se passent bien?

6. Comment souvent souhaitez-vous ne jamais avoir été dans cette relation?

7. Je ressens encore une forte connexion avec mon/ma partenaire

8. Si j'avais à revivre ma vie, je choisirais la même personne comme partenaire (marier, vivre avec, fréquenter)

9. Notre relation est forte

10. Je me demande souvent s'il y a quelqu'un d'autre qui serait un/une meilleur(e) partenaire pour moi

11. Ma relation avec mon/ma partenaire me rend heureux

12. Ma relation avec mon/ma partenaire est chaleureuse et confortable

13. Je ne peux pas imaginer mettre fin à ma relation avec $\mathrm{mon} / \mathrm{ma}$ partenaire

14. Je sens que je peux me confier à mon/ma partenaire sur absolument tout

15. J'ai eu récemment des doutes sur cette relation

16. Pour moi, mon/ma partenaire est le/la partenaire romantique parfait(e)

17. Je sens vraiment comme si je fais partie d'une équipe avec mon/ma partenaire

18. Je ne peux pas imaginer une autre personne me rendre aussi content que le fait mon/ma partenaire

19. Comment enrichissante est votre relation avec votre partenaire?

20. Dans quelle mesure votre partenaire répond-il/elle à vos besoins ?

21. Dans quelle mesure votre relation a-t-elle répondu à vos attentes initiales?

22. En général, à quel point êtes-vous satisfait de votre relation?

23. Comment est votre relation comparée à celle des autres personnes de votre entourage?

24. Appréciez-vous la compagnie de votre partenaire?

25. Comment souvent avez-vous du plaisir avec votre partenaire?

26. Quel est le choix qui décrit le mieux vos sentiments envers votre relation? 
27. Quel est le choix qui décrit le mieux vos sentiments envers votre relation? Mauvaise ou Bonne?

28. Quel est le choix qui décrit le mieux vos sentiments envers votre relation ? Pleine ou Vide?

29. Quel est le choix qui décrit le mieux vos sentiments envers votre relation ? Solitaire ou Amicale?

30. Quel est le choix qui décrit le mieux vos sentiments envers votre relation ? Solide ou Fragile?

31. Quel est le choix qui décrit le mieux vos sentiments envers votre relation? Décourageante ou Pleine d'espoir?

32. Quel est le choix qui décrit le mieux vos sentiments envers votre relation ? Agréable ou Misérable?

\section{Supplementary Files}

This is a list of supplementary files associated with this preprint. Click to download.

- APPENDIXA.docx 